\title{
Upravljanje otpadom od hrane kao deo cirkularne ekonomije: uticaj na ugostiteljstvo i hotelijerstvo
}

\section{Food waste management as a part of circular economy: impact on restaurant and hotel industry}

\author{
Dr Dragan Živković1* ${ }^{1 *}$ Dr Pero Petrović2 ${ }^{2}$ Dr Marina Protić ${ }^{3}$ \\ ${ }^{1}$ Hotel Mažestik, Beograd, Srbija / Hotel Majestic, Belgrade, Serbia \\ 2Institut za međunarodnu politiku i privredu, Beograd, Srbija / \\ Institute of International Politics and Eonomics, Belgrade, Serbia \\ 3Univerzitet MB, Fakultet za poslovne i pravne studije, Beograd, Srbija / \\ University MB, Faculty of Busines and Law Studies, Belgrade, Serbia \\ *Autor za prepisku / Corresponding author
}

Rad primljen / Received: 23.12.2020, Rad prihvaćen / Accepted: 11.05.2021.

Sažetak: U radu se objašnjava značaj i ekonomski efekti upravljanja otpadom od hrane kao vrlo bitnom segmentu cirkularne ekonomije. Posebna pažnja se obraća na analizu Projekta UNDP-a i Vlade RS, u partnerstvu sa privatnim sektorom akademskim ustanovama, kreativnim industrijama i organizacijama civilnog društva. Radi se o promeni linearnog pristupa proizvodnji i potrošnji (uzmi-napravi-baci) u pravnoj cirkularnoj ekonomiji, između ostalih i u sektoru viškova hrane (osim plastike, tekstila i nameštaja). $U$ to smislu UNDP je definisao i testirao inovativne finansijske mehanizme da bi se postavili finansijski okviri za obuhvat cirkularne ekonomije u upravljanju viškovima hrane. Smatra se da bi to uticalo na povećanje zaposlenosti u ugostiteljstvu i hotelijerstvu. $U$ cilju realizacije početne inicijative (potencirana i pojavom pandemije) smanjenja viškova hrane, organizovana je serija radionica u partnerstvu sa Ministarstvom zaštite životne sredine, privrednom komorom privatnim kompanijama, bankom hrane, udruženjem ugostiteljskih objekata i socijalnim preduzećima, radi smanjenja otpada od hrane i opcija za korišćenje viškova hrane kao resursa. I u uslovima opšte privredne krize, izazvane aktuelnom pandemijom, cilj cirkularne ekonoije jeste tranzicija i razvoj društva u društvo u kome je nastanak otpada sveden na minimum, uz nova radna mesta, za preventivno (edukativno) upravljanje svim vrstama otpada, a naročito otpadom od hrane.

Ključne reči: Cirkularna privreda, upravljanje, otpad od hrane, pandemija.

\begin{abstract}
The paper explains the importance and economic effects of food waste management as a very important segment of the circular economy. Special attention is paid to the analysis of the UNDP Project and the RS Government, in partnership with the private sector to academic institutions, creative industries and civil society organizations. It is about changing the linear approach to production and consumption (take-do-throw) in the legal circular economy, among others in the food surplus sector (except plastics, textiles and furniture). In this regard, UNDP has defined and tested innovative financial mechanisms to set financial frameworks for the inclusion of the circular economy in food surplus management. It is believed that this would affect the increase of employment in the catering and hotel industry. In order to implement the initial initiative (emphasized by the emergence of a pandemic) to reduce food surpluses, a series of workshops was organized in partnership with the Ministry of Environment, the Chamber of Commerce, private companies, food banks, catering associations and social enterprises to reduce food waste and
\end{abstract}


options for using surplus food as a resource. Even in the conditions of the general economic crisis, caused by the current pandemic, the goal of the circular economy is the transition and development of society into a society in which waste generation is minimized, with new jobs, for preventive (educational) management of all types of waste, especially food waste.

Keywords: Circular economy, management, food waste, pandemic.

\author{
${ }^{1}$ orcid.org/0000-0002-5022-2651, e-mail: dragan.zivkovic@majestic.rs \\ 2orcid.org/0000-0002-8908-6431, e-mail: pbp954@gmail.com \\ 3orcid.org/0000-0002-3662-5488, e-mail: majaprotic@yahoo.com
}

\section{UVOD / INTRODUCTION}

Uticaj pandemije je dugotrajno trajao na ekonomiju i turizam mnogih zemalja zbog niza restrikcija (karantin, lokdown, zataranje granica i drugih vrsta blokada). Pandemija je, između ostalog potencirala značaj cirkularne ekonomije, a posebno onaj segment koji se odnosi na hranu. U uslovima globalne ekonomske krize ljudi su navikli da žive u harmoniji gde se hrana proizovdi od sirovina, ista se prodaje $u$ što većem obimu, i na kraju se baca. Međutim, ovaj model više ne funkioniše (Vukadinović, 2018). Jedan od problema koji je izazvala pandemija je i nedostatak transparentnih informacija o upravljanju otpadom od hrane i to onaj edukativni aspekt kao i zaustavljanje otvaranja novih radnih mesta. Procenjuje se da se u Srbiji, na godišnjem nivou, odvoji preko 12 miliona tona otpada od kojih se čak 10 miliona tona ne prerađuje nego zagađuje životnu sredinu, pa i mnoge turističke destinacije (Agencija za zaštitu životne sredine, 2020). S druge strane, treba imati u vidu da je osnovni cilj upotrebe cirkularne ekonomije regeneracija devastiranih prirodnih resursa, zadržavanje sirovina u upotrebi i produženi životni vek proizvoda, a ne da doprinose zagađenju (Tripković, Arsić Dobričanin, 2021). Smatra se da više od dva miliona tona komunalnog otpada koji se odvozi na deponije moglo bi da bude ponovo upotrebljeno u proizvodnji ili za dobijanje „zelene energije“ (Petrović, 2018). Pandemija izazvana virusnom infekcijom predstavlja savremenu planetarnu opasnost sa nepovoljno istraženim trendovima u svim sferama ljudske egzistemcije (Živković, Petrović, Ercegović, 2021). Najnovija kriza, od 2020 godine, kao i one iz 2008 i 2014 godine, ponovo će zaustaviti, pa i unazaditi razvoj malih i srednjih ekonomija (Živković, Petrović, Ercegović, 2020). Inicijativa o odgovornom upravljanju otpadom od hrane koja je preduzeta 2019 godine izuzetno je dobila na značaju pojavom pandemije Naime, mnoge zemlje i ugostiteljski objekti nastojali su da otpad od hrane svode na najmanju moguću meru. Preduzete su mere za identifikaciju i uklanjanje regulatornih prepreka sa kojima se kompanije suočavaju u unapređivanju cirkularnosti svog poslovanja i promovisanja dobrih praksi i modela cirkularnog poslovanja kao i zajedničku izradu mape puta za cirkularnu ekonomiju u Srbiji. Između ostalog turistički privredni subjekti odnosno ugostiteljstvo i hotelijerstvo treba da kreiraju strateške planove koji će definisati željene ishode i identifikovati glavne korake ili rezultate neophodne za dostizanje postaljenih ciljeva. Planovi se odnose na upravljanje viškovima hrane u turističkim (ugostiteljskim) objektima. Projekat „Upravljanje otpadom od hrane“ pokrenuo je NALED u partnerstvu sa kompanijom „Eso Tron", Ministarstom zaštite životne sredine, Ministarstvom poljoprivrede, šumarstva i vodoprivrede, Agencijom za zaštitu životne sredine, Upravom za veterinu, Inspekijskim organima, i lokalnim samoupravama, s predviđenim periodom realizacije od januara 2018 do juna 2021 godine. Cilj projekta, odnosno polazna hipoteza, je unapređenje upravljanja otpadom od hrane u Srbiji, da se kreiraju regulatorna rešenja i unaprede tokovi ovog otpada. Međutim, u periodu od pojave pandemije, suštinski se nisu menjali stavovi o upravljanju otpadom, što je verovatno, posledica nepoznavanja problema ove vrste pandemije, odnosno neselektivnog tretiranja pojedinih vrsta otpada.

\section{MATERIJALI I METODE / MATERIALS AND METHODS}

Motiv za pisanje ovog rada bila je želja da se i u uslovima pandemije koja se pogubno odrazila na poslovanje ugostiteljstva i hotelijerstva, istraži mogućnost boljeg upravljanja otpadom od hrane iz višestrukih razloga (zdravstvenih, socijalnih, ekonomskih i dr.). Stoga je cilj ovog rada da ukaže na veliki značaj upravljanja otpadom od hrane kako u domenu prevencije tako i sa aspekta njegovog adekvatnog odlaganja i korišćenja. U razmatranju opredeljenog predmeta istraživanja, shodno cilju rada, korišćene su sledeće metode istraživanja: metoda analize i sinteze, jer se rad zasniva na ključnim strateškim dokumentima i programima i merama nadležnih organa, u kontroli i suzbijanju krize izazvane pandemijom. Potom, korišćena je relevantna stručna literatura i zvanične publikacije i dokumenta, pa je bilo neophodno izvršiti adekvatnu selekciju, 
obradu i analizu relevantne teorijske građe i rezultata prethodnih istraživanja u navedenoj oblasti. Zatim je korišćena metoda komparacije i analogije, u smislu donošenje mera ugostiteljskih i hotelijerskih preduzeća. Prema podacima Evropske agencije za životnu sredinu otpad od hrane koji nastaje u domaćinstvima i hotelijerstvu sačinjava $61 \%$ komunalnog otpada te ga je trebalo multidisiplinarno analizirati. Bitna je bila i metoda deskripcije u smislu opisa stanja i mera u kriznoj situaciji i predviđanja budućih odluka i mera. S obzirom na polaznu hipotezu (značaj i efekte cirkularne ekonomije i upravljanje otpadom od hrane sa zdravstvenog i ekonomskog aspekta) primenjena je i metoda verifikacije. $U$ radu se posebna pažnja obraća na analizu Projekta UNDPa i Vlade RS, u partnerstvu sa privatnim sektorom, akademskim ustanovama, kreativnim industrijama $i$ organizacijama civilnog društva. Radi se o promeni linearnog pristupa proizvodnji i potrošnji (uzminapravi-baci) u pravnoj cirkularnoj ekonomiji, između ostalih i u sektoru viškova hrane (osim plastike, tekstila i nameštaja). U tom smislu UNDP je definisao i testirao inovativne finansijske mehanizme da bi se postavili finansijski okviri za obuhvat cirkularne ekonomije u upravljanju viškovima hrane. Smatra se da bi to uticalo na povećanje zaposlenosti u ugostiteljstvu i hotelijerstvu (https:www.rs.undp.org 25.05.2021). Od 2,3 miliona tona komunalnog otpada, procene su da gotovo 900.000 tona čini otpad od hrane koji se proizvede "od njive do trpeze“ $\mathrm{i}$ kojeg stvaraju domaćinstva, ugostiteljski i javni sektor (Agencija za zaštitu životne sredine, 2018). Analiza Projekta „Upravljanje otpadom od hrane“ je imala za zadatak da ukaže na nedovoljno poznavanje ove oblasti. Projekt je značajan sa dva aspekta: (1) upravljanje otpadom od hrane i svođenje njegove količine na razumnu meru u ugostiteljstvu i hotelijerstvu; i (2) povećani nivo zapošljavanja u turizmu sa više aspekata (od lokalnog i republičkog nivoa do pojedinih privrednih subjekata u turizmu). Na osnovu iskustva drugih privreda i dostupne stručne literature, u oblasti upravljanja sistemom i tehnološkim postupcima prerade kuhinjskog otpada, u restoranima i hotelima, prikazano je sadašnje stanje sistema i njegovi nedostaci i date su preporuke za unapređenje, čak i u uslovima pandemije, koja se katastrofalno odrazila na poslovanje gotovo svih ugostiteljskih i hotelskih privrednih subjekata, a naročito onih vezanih za inostrane turiste, odnosno goste. Kriza izazvana pandemijom ostaviće ozbiljne i teške posledice po privrede svih zemalja, a tada model cirkularne ekonomije dobija na značaju (Mihaljica, 2020). Posebno će biti pogođene one ekonomije u kojima turizam i usluge čine bitnu privrednu strukturu s velikim učešćem u stva- ranju društvenog proizvoda i zapošljavanju stanovništva.

\section{REZULTATI I DISKUSIJA / RESULTS AND DISCUSSION}

Uticaj pandemije (s permanentnom ekspanzijom, dramatičnom eskalacijom i katrastofalnim reperkusijama) tokom poslednjih godinu dana imperativno je zahtevao sveobuhvatni pristup u obuzdavanju te ogromne pošasti (Živković, Petrović, Ercegović, 2021). NALED (Nacionalna alijansa za lokalni ekonomski razvoj) kao najveće i najuticajnije javnoprivatno udruženje, koje u svom članstvu ima preko 300 društveno odgovornih kompanija, lokalnih samouprava i organizacija civilnog društva, procenjuje da bi ponovnim korišćenjem svih vrsta materija iz otpada bi se otvorilo 30.000 novih radnih mesta (Guzina, 2020). To proizilazi iz Programa za uvođenje cirkularne ekonomije koji je predložio NALED sa fokusom na bolje iskorišćenje otpada od hrane, ambalažnog i elektronskog, i električnog otpada. Međutim, Srbija ne poseduje zakonsku regulativu koja se posebno odnosi na upravljanje otpadom od hrane odnosno biorazgradivim otpadom. Procenjuje se da u upravljanje otpadom od hrane zaslužuje mnogo veću pažnju menadžmenta u hotelima i ugostiteljskim objektima. U Srbiji, ukupno u toku godine, ugostitelji nabave 123.000 tona hrane od čega se $20 \%$ odmah odbaci jer su u pitanju nejestivi delovi (ljuske, kore, kosti, i dr.) a još $15 \%$ ostane nepojedeno u tanjirima i odbačeno (https://www.rs.undp.org. 25.05.2021). Međutim, čak $99 \%$ otpada, koji nastaje u ugostiteljskim objektima završi na deponiji odakle se u vazduh oslobađa etan i ugljen-dioksid. Ovaj otpad se može iskoristiti u proizvodnji biodizela i bioetanola, hrane za životinje, električne energije iz biogasa, kompostiranje i dr. Ova vrsta otpada može ponovo da se iskoristi u privredi za kreiranje nove vrednosti a, što je naročito bitno, i da uposli nove radnike na poslovima očuvanja životne sredine. Međutim, veliki problem predstavlja nedostatak infrastrukture, od posebnih kontejnera za odvajanje otpada do adekvatnih sanitarnih deponija. Srbija ima samo 10 sanitarnih deponija-odlagališta i više od 120 opštinskih koje ne zadovoljavaju ni minimum standarda. Osim toga, postoji čak 2.170 divljih deponija (mada se procenjuje da ih ima više od 3.500) koje se nalaze u blizini naseljenih mesta i vodotokova (https://www.rs.undp.org. 25.05.2021). U praksi su se kao najveći proizvođači otpada od hrane pokazale javne institucije, najpre zdravstvene ustanove, potom objekti iz ugostiteljskog sektora. Na uzorku od 250 ispitanika, od kojih je 50 iz zdravstvenih ustanova a 200 iz ugostiteljskog sektora dobijen je rezultat uporednog istraživanja, koje je obavljeno u 
drugoj polovini 2019 godine. Po tom rezultatu 21,1\% ispitanika poseduje znanje o pravilnom upravljanju otpadom od hrane (NALED, 2021). Cilj Projekta, koji je predvodio NALED, bio je da za 50 odsto uveća ovo znanje, te da se poveća procenat, na $31-32 \%$, onih koji znaju pravilno da upravljaju ovom vrstom otpada. Prema podacima istraživanja zdravstvene organizacije (uglavnom bolnice, stacionari i banje), u proseku, proizvedu oko $28 \mathrm{~kg}$ otpada od hrane na dnevnom nivou, dok se u ugostiteljskim objektima proizvede, dnevno, otprilike oko 8 kilograma. Sektor ugostiteljstva naručuje oko 120 hiljada tona namirnica godišnje od kojih trećina završi na deponiji
(NALED, 2021). S druge strane, oko $66 \%$ svih zdravstvenih ustanova i ugostiteljskih objekata obavlja primarnu separaciju hrane od komunalnog otpada, a blizu petine ugostiteljskih objekata, sav otpad od hrane odlažu u komunalni otpad, odnosno ne obavljaju odvajanje.

Strategija razvoja turizma Republike Srbije za period 2016-2025 godine pokazuje da većina objekata ovom vrstom otpada ne upravlja na predviđen način, pa je neophodno pojačati kontrolu ali i edukaciju generatora prema obavezama koje proističu iz Zakona.

Tabela 1 - Broj preduzeća iz oblasti turizma i ugostiteljstva u Srbiji 2016. godine

Table 1 - Number of companies from tourism and restaurant industry in Serbia in 2016

\begin{tabular}{|c|l|c|}
\hline Oznaka & Delatnost iz oblasti turizma i ugostiteljstva & Broj preduzeća \\
\hline 5510 & Hotelski smeštaj & 532 \\
\hline 5520 & Odmarališta i slični objekti za kraći boravak & 86 \\
\hline 5610 & Delatnost restorana i pokretnih ugostitelj. objekata & 14.134 \\
\hline 5621 & Ketering & 85 \\
\hline 5629 & Ostale usluge pripremanja i posluživanja hrane & 6.973 \\
\hline & UKUPNO & 21.725 \\
\hline
\end{tabular}

Izvor: Strategija razvoja turizma R.Srbije 2016-2025 (SI.glasnik RS 98/2016).

Ostaci od hrane, nakon korišćenja mogu veoma negativno da utiču na zdravlje ljudi vraćanjem u lanac ishrane (npr. ishrane životinja) ili kad dospeju na deponije na kojima, pod otvorenim nebom, emituju štetne gasove, sa efektom staklene bašte. Višak hrane koji se pojavljuje u svakoj od faza, počevši od primarne proizvodnje pa do krajnje upotrebe, u Srbiji uobičajeno zaršava u komunalnom otpadu i sačinjava $60 \%$ od ukupnog otpada na deponijama. Zbog sve većih količina i nepravilnog upravljanja otpadom od hrane, kao i opasnosti koje predstalja po zdravlje ljudi analizirani Projekt se odnosi na podizanje svesti o značaju ovog problema kao i o mogućim rešenjima regulisanja tokova ove vrste otpada (NALED, 2020). Na primer, EU legistativa predviđa da države članice treba da preduzmu mere za sprečavanje i smanjenje otpada od hrane u skladu sa Programom za održivi razvoj do 2030 godine UN-a od 25 septembra 2015 godine (Živković, Petrović, Ercegović, 2019). Cilj Direktive EU je da se postepeno u svim državama članicama podstaknu potrebna ulaganja u upravljanju otpadom i omogući razvoj cirkularne ekonomije od proizvodnje do potrošnje, odnosno ponovne upotrebe i proizvodnje, te vraćanje korisnih sirovina u cirkularnu ekonomiju (Direktiva, 2018). U Srbiji se tek kreira i kompletira legistativa o upravljanju otpadom i inoviranje postojećih strategija (Strategija, 2010). U toku je izrada strategije za upravljanje otpadom za period 2021-2030 godine koja bi trebalo da propiše nove mere, preporuke i ciljeve za upravljanje otpadom, uključujući i biorazgradivi otpad. Zakonom o upravljanju otpadom i Pravilnikom o upravljanju otpadnim uljima, regulisano je upravljanje, odnosno predviđeno je sakupljanje i predaja otpadnog jestivog ulja ovlašćeni operaterima za ugostiteljske objekte koji dnevno pripremaju više od 50 obroka. Predaju prati Dokument o kretanju otpada, a podaci o generisanim količinama se prijavljuju Agenciji za zaštitu životne sredine kroz Nacionalni registar izvora zagađenja. Procenjuje se da su ulaganja u zaštitu životne sredine četiri do pet puta manja nego u zemljama Evropske Unije i iznose 0,3\% BDP-a, a u privredi postoji veliko interesoanje za prelazak na cirkularnu ekonomiju (Petrović Pavlović, 2018). To se posebno odnosi na turističku privredu (ugostiteljstvo i hotelijerstvo) koja posluje po međunarodnim standardima i sa aspekta upravljanja otpadom od hranljivih materijala. Međutim, istraživanja su pokazala da je neophodna preciznija zakonska regulativa iz ovog domena. U tom kontekstu kreiran je i „Vodič za upravljanje otpadom od hrane" koji je namenjen učesnicima sektora za ugostiteljske usluge, kao i drugim privrednim i javnim subjektima koji generišu otpad od hrane. Pokazatelji uspešnosti programa ogledaće se kroz sakupljanje 1000 tona otpada od hrane i u vidu podizanja nivoa znanja velikih proizvođača otpada od hrane, o pravilnom upravljanju otpadom, u okviru 50 odsto 
minimalno (NALED, 2019). Izmena i dopuna Zakona o upravljanju otpadom koja je planirana za naredni period, odnosno kreiranju potpuno novog zakona o upravljanju otpadom moglo bi omogućiti pravni osnov za izradu Pravilnika koji bi sadržavao osnovne odredbe na način postupanja sa ovom vrstom otpada, a s druge strane omogućilo i otvaranje novih radnih mesta. Predloženi ciljevi i aktivnosti koji se mogu apostrofirati, iz Projekta i Strategije upravljanja otpadom u Republici Srbiji mogu se sistematizovati u šest setova (NALED, 2021):

- Harmonizacija politika i propisa u oblasti upravljanja otpadom od hrane;

- Kampanja za podizanje svesti o odgovornom upravljanju otpadom od hrane;

- Edukacija republičkih i lokalnih inspekcija o upravljanju biootpadom;

- Pilotiranje sistema prikupljanja otpada od hrane u javnim institucijama i prirednim subjektima na nivou lokalne samouprave;

- Povećanje inspekcijskog nadzora i savetodavne posete generatorima u vezi s primenom propisa o otpadnoj hrani;

- Uputiti velike generatore otpada od hrane u procedure za odgovorno odlaganje i povećanje njihovog broja na 50 odsto.

Krajnji, dugoročniji cilj, koji proizilazi iz istraživanja, je da se 1000 tona otpadne hrane deponuje kao sirovina operatera za reciklažu. Odgovorna potrošnja i proizvodnja predstavljaju jedan od najbitnijih zadataka održivog razvoja (Eurostat 2018).

\section{ZAKLJUČAK / CONCLUSION}

Primenom koncepta cirkularne ekonomije u ugostiteljstu i hotelijerstvu turistička prireda Srbije bi dobila mogućnost za ubrzaniji razvoj, a društvo i građani kao i turisti bi dobili mogućnost za dalje unapređivanje i zaštitu životne sredine po osnovu šire primene smanjenja otpada, kao i otvaranja novih radnih mesta koja bi se kreirala u sektoru prerade otpada svih vrsta a posebno otpada od hrane. Istraživanja pokazuju da samo $13 \%$ ugostiteljskih objekata već koristi usluge operatera za sakupljanje i pravilan tretman otpada od hrane, kao i da u većini ovih objekata stav je da se u Srbiji otpad od hrane, uglavnom baca u kontejner i transportuje na deponiju (NALED, 2020). Analiza je ukazala na nastojanje hotelijera da se to promeni i time poveća zaposlenost, smanje troškovi poslovanja i napravi značajan pomak u očuvanju životne sredine, pravilno tretirajući otpad uz preventivno upravljanje, kako bi se on sveo na najmanju moguću meru a potom adekvatno upravljalo sa njegovim umanjenim obimom. Drugi bitan segment u upravljanju otpadom je neophodnost proaktivnog delovanja i edukacija putem formalnog i nefor- malnog programa obuke. Potrebna je i edukacija postojećeg kadra u ugostiteljstvu i hotelijerstvu kako izršilaca poslova tako i upravljačkog dela privrednih subjekata u ovom sektoru, ali i angažovanje stručnih lica i eksperata iz okruženja. Predlog Programa NALED-a ukazuje da je za razvoj cirkularne ekonomije, koja se odnosi na ugostiteljstvo i hotelijerstvo, neophodan razvoj menadžmenta za upravljanje otpadom od hrane. To se, prvenstveno odnosi na upravljanje ekonomičnošću i efektivnošću u korišćenju namirnica da bi se smanjio obim ostataka. S druge strane, to iziskuje otvaranje takvih radnih mesta, za preventivno i korektivno delovanje. Upravljanje otpadom od hrane posebno dobija na značaju pojavom dugotrajnijih opštih kriza kao onima izazvanih pandemijom, jer zdravsteni razlozi se tada dovode u prvi plan, mada i nestašica hrane, u takvim uslovima, može predstavljati ozbiljan problem za svaku državu. Ugostiteljske i hotelijerske organizacije sve više prihvataju obrazac ponašanja i nešto na čemu će se graditi određena konkurentska prednost kompanija iz ovog sektora. Načelo hijerarhije upravljanja otpadom upravo nalaže da se svaka primarna aktivnost upravljanja otpadom smatra sprečavanje njegovog nastanka. $\mathrm{S}$ tim u vezi, donošenje adekvatne regulative $u$ ovoj oblasti imalo bi veliki uticaj na smanjenje količina generisanog otpada od hrane i na značajno smanjenje troškova uspostavljanja i upravljanja ovim sistemom. Takođe treba predvideti odgovarajuće ekonomske instrumente radi efikasnosti upravljanja ovim otpadom.

\section{LITERATURA / REFERENCES}

[1] Agencija za zaštitu životne sredine, Upravljanje otpadom u Republici Srbiji od 2011. do 2017. godine, Beograd, 2018.

[2] Direktiva Saveta Evrope 2008/98/EC o otpadu i Direktiva 2018/851/EC o izmeni direktive 2008/ 98/EC o otpadu.

[3] Eurostat (2018). Sustainable development in the European Union - Overview of progress towards the SDGs in an EU ontext. Aviable at: https//ec.europa/eurostat/web/productsstatistical-books/-/KS-01-18-656.

[4] Guzina, V. (2020). Ekonomske posledice korone, Politika, Beograd, 27.04.2020, str.18.

[5] Mihaljica, M. (2020). Spasavanje obolelih, ali i ekonomije, Politika, Beograd, 01.04.2020.

[6] Petrović, D., Pop-Lazić, I., Petrović, P. (2019). Uticaj preduzetništva u cirkularnoj ekonomiji na regionalni razvoj, Univerzitet u Nišu, Ekonomski fakultet Niš, XXIV naučni skup: Regionalni razvoj i demografski tokovi zemalja Jugoistočne Evrope, str. 413-42. 
[7] Petrović, P., Pavlović, Đ. (2019). Zapošljavanje i preduzetništvo u cirkularnoj ekonomiji, Simpozijum PIM 08, VTŠSS Zrenjanin.

[8] Petrović, P. (2019). Srbija u novom društvenoekonomskom sistemu, Institut za međunarodnu politiku i privredu, Beograd.

[9] Strategija upravljanja otpadom za period 20102019, Službeni glasnik RS, br.29/2010.

[10] Tripković, A., Arsić, Lj., Dobričanin S. (2021). Izazov funkcionisanja i razvoja malih i srednjih preduzeća u cirkularnoj ekonomiji, Ecologica, 28 (101), 50-56.

[11] Vukadinović, P. (2018), Ekonomija između linearne i cirkularne ekonomije, Ecologica, 27(98), 231-236.

[12] Živković, D., Ercegović, M. (2020). Način funkcionisanja malih i srednjih preduzeća u hotelijerstvu i eko-turizmu, Ecologica, 27(97), 75-81.

[13] Živković, D., Petrović, P., Ercegović, M. (2021). Uticaj pandemije na razoj tercijalnih delatnosti, Ecologica, 28(101), 99-104. 